The measurement given in each case is the ratio of the actual measurement of the part to the entire length of the brain expressed in hundredths. The symbol ${ }^{3} \vee \bar{L}$. B. D. indicates the cubə root of the product of the length, breadth, and depth of the prosencephalon, thus giving us the means of comparing the bulk of that important part of the brain in different birds. In Fu'ica the dimensions expressed above are: for the rhinencephalon, length, 14.2 ; breadth, 18 ; the lobes project and are not fused: prosencephalon, length, 73 ; breadth, 90; depth, 55 ; ${ }^{3} \bigvee$ L. B. D. 71.22 ; mesencephaton, length, 27 ; breadth, 22 ; epencephalon, length, 50 ; breadth, 33 ; depth, 38 ; metencephalon, length, 40; breadth, 33; depth, 22; length of brain, $22 \mathrm{~m} \mathrm{~m}$. In the duck we find, for the rhinencephalon, length, I6; breadth, I3; prosencephalon, length, 74 ; breadth, 87 ; depth, $54 ; 3 \vee$ L. B. D 693 ; mesencephalon, length, 33 ; breadth, 23 ; epencephalon. length, 26 ; breadth, 33 ; depth, 43 ; metencephalon, length, 50; breadth, 33 ; depth, 30 ; length of

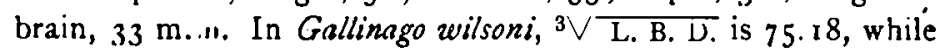
in Ardea herolias, it is $58 .+3$, showing how far our species (Fulica, 71.22 ) is above the herons.

\title{
EMBRYOLOGICAL NOTES ON THE BRAIN OF THE SNAKE.
}

C. L. HERrick,

With Plates XV-XIX.

A few isolated memoranda from a larger number gathered during the present year, are here presented, with especial reference to certain morphological problems.

General Description. The embryos in question represent three stages from Eutania and one from the black snake, the latter being a little older than the oldest garter-snake em'ryo. The youngest embryo is somewhat less mature than the youngest figured by Rathke. ${ }^{1}$

Rathke's embryo possessed but two pairs of gill clefts while

IRathke, H. Eatwicklungsgeschicte der Natter, 1839. Plate I, Figs. I-5. 
ours had three perforate and one cleft which may not have been perforate. This stage was secured in Granville, O., June gth. Plate XVI, Fig $\mathbf{r}$, shows the genetal appearance while Fig. 2 is an enlarged drawing of the head (camera outline.) The eye is in a primitive condition, the lense capsule still cohering with the skin and unclosed. The cervical flexure is more than 45 degrees, the mesencephalic flexure more than 90 degrees. The diencephalon is still much longer and larger than the primary prosencephalic vesicle. The nasal sacs have not yet formed and the olfactory epithelium is connected with the hypophysis anlag and lense capsule by a continuous band of sensory epithelium. The point on the ventral surface where the great mesencephalic flexure is pivoted is obviously the angle of the jaw, or the region of the hypophysis (pituitary.) Rathke is correct in saying that the latter body is not as yet formed, but its anlag as a thickened patch of epithelium is quite obvious. Plate XIX, Fig. I, (207.5.) The recognition of the region of the hypophysis as the morphological front of the head serves to interpret for us several of the most difficult problems of comparative morphology. The morphological front of the brain is the region of the infundibulum, from which the true terma may be traced cephalo-dorsad. The diverticles beyond this point are all from the dorsal or dorso-lateral aspects of the brain. These may be counted as follows: recessus opticus, primary prosencephalic vesicle, dorsal sac, epiphysis, and roof of the thalamus proper. If this interpretation could be accepted, the præ-commissura, callossum, hippocampal commissure, habena and supra-commissures, are all analogous structures. The sen. sory epithelium of the forehead region gives rise to ( 1 ) hypophysis, (2) Jacobson-nasal structure, (3) lense capsule. It is possible that the latter belongs to the epidermal area corresponding to the mesencephalon and that it has been excentrically displaced by the rapid arching of the head. We would recognize the existence of a lateral sensory epithelium band which is strictly lateral in the post-cephalic regions and becomes symmetrically segmental forming the lateral line system. In the region of the gill clefts this system gives rise to the branchial sensory organs. Cephalad of this point the strong and irregular growth and fiexures serve to disarrange the primitive simplicity of the epithe. 
lium. The ear-capsule, lense-capsule and sensory pits of the head (in fishes) are to be included. The strong confirmation which these views have recently received from the study of Amphioxus and Ammocetes is elsewhere referred to.

It will be noticed that the surface from the angle of the mouth to the nasal end of the head is nearly in one straight line.

The next stage is from embryos taken June I Ith. Growth during this period is very rapid and in order to secure consecutive stages a large amount of material would be needed. The lense has closed and separated from the skin. The gill clefts have closed with the exception of a single pair. (The posterior pairs were not made out as distinct openings in any of the speci. mens examined.) The nasal sacs have been formed and extend from immediately cephalo-ventrad of the eye toward the cephalo. ventral aspect of the head. It can be readily seen that the growth is from ventro caudad cephalo-dorsad; i.e., that the epithelium is driven up into the pits by proliferation in that di. rection. In accordance with the suggestion just made, the growth is from the pituitary reginn caudad (morphologically) and, as in Amphioxus the nasal and pituitary structures are associated, so here at first the same relation prevails. It may also be noted that the protrusion of the recessus opticus and the infundibulum are causing the palatal area to be flexed. The whole cerebral part of the head is being flexed dorsad, -as may be seen by examining later stages. There is as yet no external evidence of trunk segmentation but the medulla is strongly segmented and produces a superficial node-like appearance behind the ear. (Plate XVI, Fig. 3.)

The third stage is represented by Eutænia embryos taken June I $5^{\text {th. }}$ The germinal disc covered three-fourths of the yolk and the tail described three turns. (Plate XVI, Figs. 4, 5.) The backward flexure of the front of the head is still more marked and the nasal sacs are carried cephalo-dorsad. The myomers of the trunk and tail are prominent.

In this stage the lense is beginning to fill out the capsule and the retina has stongly differentiated from the pigment layer, but the primary optic vesicle has not closed and the optic fibers have not begun to appear.

The pituitary is just forming and has not called out any re- 
sponsive development in the infundibulum. The cephalic sensory epithelium remains as a continuous band along the palatal surfaces, but is thickened at the ridge bordering the mouth laterally, from which point it can be traced into the nasal epithelium.

The remaining embryos at our disposal are from a black snake killed July I gth. 'These seem to be relatively less developed than the last mentioned. (Plate XVI, Figs. 6, 7.) No special description is necessary. as the differences are all such as may be explained as connected with the peculiarities of the type. The above embryos will be referred to as E. I, E. II, E. III, and C IV respectively.

The Dorsal Sensory Plate. - In reptilian embryos of early stages the existence of a continuous sensory plate from the hypophysis (pituitary) to the auditory region is very obvious. In very early stages the front of the embryo coincides with the future infundibulum and the subsequent growth only increases the dorsal surfaces without adding anything to the ventral. The nasal sacs, lense capsule, and sensory epithelium of the gill-clefts is one continuous plate differing from the re. mainder of the ectoderm in its greater thickness and columnar character. The epithelium has the proliferating power so characteristic of the sensory epithelia and gives rise to its own gang. lia and nerves. It would be natural to seek further homologies in the lateral line organs.

In embryos of Eutænia of the age figured (Plate XVI, Fig. 1,) the olfactory pits are not formed but the dorsal sensory plate is thickened cephalo dorsad of the lense capsule. In Fig. I, Plate $\mathrm{XV}$, a portion of a section is shown which on the left side illustrates the formation of the lense capsule but this section does not show, what may be readily seen in others of the same brood but less advanced, that the lense-capsule epithelium is continuous with another portion of the sensory plate of the frontal region. Along the caudal regions this epithelium is continuous with a thin membranous portion with flat cells. Tracing this layer cephalad over the convexity of the primitive vesicle it shows a tendency to thicken and to invaginate until it fuses with the epithelium of the pituitary anlag. It seems to the writer that there is no reason to doubt the suggestion that the pituitary is that sensory invagination which is formed at the mor- 
phological front of the head. One cannot carefully trace the genesis of the brain and head in Ophidia without being convinced that this is the clue to the complicated problem of cephalogenesis. The query so often raised as to the reason for the restriction of the chorda to prx-infundibular regions of the head requires no further discussion if it is recognized that the pituitary marks the beginning of a dorsal surface and all structures in the skull arising cephalad of it cannot be considered as segmental in a strict sense. The stomatodeum is that portion of the ectoderm which has been phylogenetically interpolated between the primitive subterminal mouth and the present oral aperture. (See Plate XIX, Fig. I.) The structure of epithelium and the origin of the neuroblasts within it at the ofactory area is well shown in plate XV, Fig. 8, the portion forming the lense and its capsule at plate XV, Fig. 7 .

The Cranial Nerves. - In E II, the trigeminal is already quite well developed. The vesicle is moderately expanded and upon its lateral aspects a small cluster of cells is seen which, however, does not directly communicate with the medulary wall itself. On the other hand, the connection is very direct and obvious with the seat on the ectoderm at the base of the mandibular anlag. The nerve at this stage has all the characteristics of a sensory nerve arising from a special centre in the skin.

In E. II, the three divisions are well distinguished. The ophthalmic extends only as far as to a point dorso-mesad of the eye, while the combined maxiliary and mandiblar rami extend latero ventrad to the angle of the mouth, the former turning rapidly cephalo-laterad and reaching almost to the eye, while the later dips into the rapidly growing cells of the mandiblar anlag. The vesicle (caudad neuromer) is without an obvious nerve at this stage, although its neuromer is as large as any of the following ones. It would appear that its dorsal roots enter with the fifth. The seventh nerve passes directly cephalo-ventrad to the hyoid arch. It arises with the auditory. The motor cells lie on the ventro-lateral aspects but do not emerge there. The auditory ganglion arises from a special anlag formed with the capsule and for a long time does not communicate with the medulla.

Two roots arising from two neuromers caudad represent the ninth and tenth anlags, the former simply related to the gill 
cleft corresponding while the pneumogastric gives off branches to two and apparently three rudimentary clefts and also a vagus branch which passes along the mesoderm to the masses of cells in the vicinity of the future stomach. The neuromer lies immediately mesad of the auditory capsule.

In Eutænia III we note the existence of a peculiar elevated and modified area of the, ectoderm which, although it might be regarded as accidental, is sufficiently remarkable to warrant de. scription. It lies exactly over the site of the valvula cerebelli i.e. over the chiasm of the trochlearis. The area is quite conspicuous in longitudinal horizontal sections and is differentiated from the adjacent parts of the ectoderm by the commingling of peculiar nuclei with numerous deeply stained granules in a clear stroma (haematoxylin stain.) The cells are closely massed in a spheroidal body. As the sections penetrate deeper the deeply colored granules accumulate and the large epidermal cells become fewer. There is an appearance of rapid degeneration. The nuclei containing the granules vary greatly in size as well as in the size and number of the granules. There seems to besome ill-defined connection with the brain tube at the valve, but nothing very definite was observed. The observation is recorded with a view to direct attention to the possible existence of a dorsal sensory organ correponding to the trochlearis or isthmus segment. On the other hand, it must be observed that nothing similar has been seen in younger Eutænia embryos or in those of the black snake.

In $E$. III the third (oculo-motor) nerve arises from the very distinctly expanded base of the mesencephalon just cephalad of the isthmus. The cells which give rise to the fibers are formed from neuroblasts from a sharply localized area and the fibers pass out directly. It seems to me that the nerve is continually replenished by neuroblasts which pass out along the roots and add to the originally small number of cells lying in the course of the nerve. These neuroblasts evidently fuse with their predecessors in such a way that, as each neuroblast acquires a sheath, these successive portions form the Ranvier segments of the sheath of Schwann. This seems to be the uniform method of development whether within or outside of the central organ. The third nerve fibers pass ventro-cephalad and cross 
the ophthalamic which becomes smaller and loses itself near the meso-cephalic aspect of the eye. The oculo-motor terminates near disperse clusters of indifferent (muscle) cells caudad of the eye anlag.

In $E$. II the oculo-motor nerve was not recognized, though probably about forming.

In $\mathrm{E}$. II the relation of the various clefts of the visceral region is especially well shown. The hypophysis is a simple pouch-like diverticle and is in communication cephalad with the mouth cleft and caudad with the eustachian tubes diverticles of the second branchial cleft. These have already begun to assume a tubular form. The preceding clefts are imperforate, the second being represented by ectodermal and entodermal pouches which do not meet,

Neuromers in the Ophidiax Embryo. Waters has given a brief summary of the history of opinion respecting the expansions of the medullary tube which have been noticed by most embryolngists since Von Paer. ${ }^{1}$ To this paper the reader is referred for bibliography.

Balfour recognized the possibility that these "earlier constrictions may potentially correspond to so many nerve roots.

BERANECK ${ }^{2}$ in several papers attributes segmental value to these dilations, as did Kuppfer.

Orr, in studying these expansions, decides ( 1 ) that successive neuromers are separated by external dorso-ventral internal ridges, (2) that the neuromeric constrictions are symmetrical and opposite, (3) that there is a radial arrangement of cells within each neuromer, (4) that the cells are confined to their respective neuromers, there being a shape line of demarkation, (5) that the nerve roots arise from the crests of each neuromer. The first [hind brain] neuromer gives off the trigemenal, the second the abducens, the third the severth and eighth, etc., (6) that the mid-brain is not segmented while the fore-brain has two neurom-

I. Waters B. H. Primitive segmentation of the Vertebrate. Brain. Quarterly Journal of Microscopical Science. June, I892.

2. Recherches sur le developpement des nerfs craniaux chez les lezards. Recueil Zool. Suisse. 1887, and Replis medullaires du Poulet. ibidem. 
ers, and (7) that the cord is not segmented. McClure demonstrated neuromeric segmentation throughout the cord but does not agree with Orr as to the sixth nerve. He notes that the neuromers soon desappear and insists that the fore brain neuromers are homologous with those of other regions.

Waters decides that the fore-brain is composed of [three or] at least two well-marked neurumers. He says: "Of the existence of the first $I$ am in doubt. The first nerve arises in the same manner, though at an earlier period than the other cranial nerves, thus indicating. however slightly, its segmental character. From the second no nerve springs, but it is directly oppo. site to the eye, and the optic diverticula spring from its dorsal crest in a manner entirely comparable to the other cranial nerves thus pointing to the conclusion that, though highly specialized in existing vertebrates, it was originally not so closely identified with the brain itself, but was homologous with the brain itself. From the third no nerve arises, but $I$ think it probable that still lower forms in still earlier stages will show some nerve arising at this point."

(2.) "That the mid-brain consists of two neuromers from which I have every reason to believe the third and fourth nerves take origin, and hence deserve to be recognized as segmental structures."

(3.) "That the hind brain consists of six neuromeres. In regard to this region I think the observation of McClure and Miss Platt are sufficiently satisfactory except as regards the origin of the sixth nerve and the abducens neuromere. This nerve I have found to occupy its theoretical position when its neuromere exists; when fusion has taken place between the trigeminus and abducens neuromeres, the sixth nerve has been shifted backward toward the seventh and eighth nerves."

"It seems reasonably certain that the central nervous system of the primitive Vertebrate form consisted of a series of symmetrical segments, of which those of the neuron held the same relation to the mesoblastic head-segments as did those of the cord to the protovertebra, i. e. were intersomitic; that those of the head. ten or eleven in number, gave origin to their respective nerves precisely as did those of the cord to 
the spinal nerves; that, in fact, the two regions were perfectly homologous in origin, character and function."

In this connection it will be remembered that Froriep has announced metamerism of a similar sort in the case the mole (two metamers in the diencephalon and three in the mesencephalon.)

In the recent paper by the same author reviewed elsewhere in this number Froriep withdraws from this position and says that while the position of these folds may be determined by the nerves the origin of the folds is a passive mechanical result of rapid longitudal growth in a limited space. He regards them as of no morphological significance. He concludes: "The jointing of the vertebrate body is originally determined by the mid. dle germ layer; where ectodermal structures exhibit segmental arrangement it is a result of secondary adaptation to metamerism of the mesoderm."

In forming any estimate of the metameric significance of these diverticles as they undoubtedly appear in the fore brain a few fundamental considerations must be kept in mind. (1) The morphological front of the brain cannot be beyond the infundibulum. The pituitary is historically closely associated with the neuroporus on the dorsal aspect. The olfactory is allied with the pituitary but is a dorsal organ (Amphioxus, Cyclostomata.)

(2.) It is scarcely legitimate to count dorsal diverticles like those of the fore-brain with ventral expansions like those of the mid-brain and hind-brain. Waters and others seem to have made this mistake.

(3.) The optic diverticle is not to be directly compared with the others but is more like a belated portion of the ganglionic ridge. The morphological entrance of the optic fibers is caudad of the hypophysis-olfactory region

(4.) If the olfactory is the first dorsal root the ventral floor of its neuromer is in the mammillary region.

((.5) The hypoaria and their homologues may represent a second ventral expansion.

(6.) The formation of the mesencephalic flexure and saddle cleft may have played an important part in modifying the originally simple arrangement of the third and fourth nerve roots. 
(7.) The isthmus has been greatly disturbed by the formation of the cerebellum and pons. The interpeduncular body represents a rudiment which may throw light on the apparent absence of nerves from this important segment.

The study of the black snake and garter snake embryos, while not completed, suggests the following statements:

(r.) The first embryonic vesicle suffers almost complete rotation about the hypophysis (infundibulum.)

(2.) The mouth of vertebrates is terninal or sub-terminal, the stomatodeum being morphologically the modified skin of a dorsal region of the head.

(3.) The chordal part of the brain represents its enture length, the so-called pre-chordal being but revolved dorsal projections.

(4.) Prenature closing of the nerve tube due to cephalization has served to retain the homologues of certain ganglia in the medullary tube.

(5.) The formation of the primary optic vesicle is a belated separation of such a pair of ganglia.

(6.) The fibres of the special sense nerves may retain the habit of ordinary sensory fibres of producing bifurcating collaterals.

(7.) If neuromeres once existed in the fore-brain they would only be visible at an early stage and would be obscured by the altered conditions. The so-called fore-brain neuromeres differ from those of the medulla and cord in involving only dorsal structures. They are wholly illusory from a morphological point of view.

(8) The position of the optic recesses is morphologically secondary and must not be given a too prominent morphological rank.

(9) The commissures (prx., callosal, fornix, habena, supra- and post.,) are similar and belong to the dorsal system. They are interrupted by the complicated system of dorsal diverticles.

(ro) Two subdivisions occur in the base of the mesenceph. lon at an early stage but they do not correspond to the $3 \mathrm{~d}$ and $4^{\text {th }}$ nerve roots, both of which lie in the caudal member. 
(II) The isthmus is longer than any of the socalled neuromeres.

(12) The trigeminal neuromere is well and early developed. The roots of the nerve pass both cephalad and caudad into adjoining neuromeres. It is possible to regard it as representing, with the third and sixth nerves, three primary neuromeres.

(r3) The fourth hind-brain neuromere is no larger than the seventh and eighth.

(14) The fifth and sixth are nearly cqual and give rise to the ninth and tenth in a similar way. Tlie eleventh is seggregated at a late period.

(15) The cord is distinctly segmented at one period. This segmentation is of a sort inexplicable by appeal to mechanical effects of the metamerism of the protovertebrae.

(I6) The neuromeres of the medulla cannot be ascribed to the mechanical effects of the anlags of the nerves, for those segments which have no nerves develop equally with the others.

(17) The auditory sac and ganglion and other structures of this region do not enhance but rather suppress the neuromeres.

It is hoped suon to present the evidence more fully than is now possible.

The youngest stages of Eutænia at out disposal are represented by a somewhat oblique series about parallel with the middle part of the medulla. The embryos are figured on Plate XVI, Figs. I, 2. The sections, Plate XVIII, Figs. 5--9, plainly show that the medulla is distinctly segmental at this early stage and that the segments have a definite relation to the cranial nerves. There are five such expansions beginning with the trigeminal which is larger (though not so obviously as later) than the rest. In spite of the great flexures of the mesencephalon it is obviously composed of at least two parts.

Similar sections parallel to the axis of the mid-back region show that, at this stage, the neuromerism is confined to the medulla (See Fig. I 2). In the oldest specimens seen the same relations prevail except that the cephalic parts are exagerated. Plate XVIII, Figs. I-4, represented four sections nearly parallel with the medulla. The embryo from which these were taken is. figured Plate XVI, Figs. $4-5$. 
In general, the medulla may be divided into three portions: The isthmus, or that narrowed portion which lies cephadad of the trigeminus; second, the expanded portion including the neuromeres of the fifth, seventh and eighth nerves; third, the re. maining neuromeres which grade into the spinal portion. There is some evidence that the isthmus contains two neuromeres, the expanded portion contains three and the remainder two obvious expansions.

The neuromeres are well seen in Plate XVII, Figs. I-6, and in the sections from black snake embryos. Plate XIX, Figs. 4-5.

The figures of Plate XVII show the extended roof of the diencephalon at this age, also the great development of the optic and infundibular recesses. There is a recess at the cite of the future mammillaria, as in fishes. There is a thickening in the region of the pes where rapid proliferation is going on. This is obviously preparing for the extensive anastomoses described in a previous paper.

The floor of the mesencephalon is obviously composed of two portions but evidence is wanting to show that there are distinct neuromeres corresponding to the third and fourth nerves.

The first neuromere (isthmus) of the medulla is about twice the length of the others and from its roof the cerebellum is developing. The trigiminal neuromere is greatly expanded but is not longer than others. The third expansion has no root at this stage. It is not unreasonable to suppose that the trigiminal has gathered up roots from the neuromeres cephalad and caudad. It would thus represent three neuromeres, while the sixth could be looked upon as a remnant weak and small.

The fourth expansion receives the eighth from the anlag on the auditory sac and gives rise to the seventh, while the fifth and sixth neuromeres are as usual. Fig. 4, of Plate XIX indi. cates that this neuromerism is even more prominent in the cord than in the medulla. It seems impossible that these remarkable and regular changes could be due to mechanical effects of the mesoderm segments.

The Origin of the Tuber Olfactoril.-Plate XV, Figs. 9-I I gives quite a clear idea of the origin of the olfactory struc. tures. As the epithelium begins to invaginate the proliferation increases, neuroblasts accumulate on the side nearest the brain 
and soon the olfactory nerve fibres extend mesad. The devel opment of a moniliform series is very obvious. Instead of reaching the front of the cerebrum, as in other vertebrates, the lateral aspects are reached. Even before the nerves effects. entrance into the walls of the cerebrum the latter become concave. In this way is formed the large olfactory fossa which is the most remarkable peculiarity of the rhinencephalon of Ophidia. The tuber as such is not developed but the olfactory structures occupy the ventro-lateral aspects of the frontaliprotrusion of the brain, while the mesal wall is simply thinned out. 'The developed of the glomerulary structures has not yet been followed in detail but it seems probable that a number of neuroblasts actu. ally adhere to the cerebral surface and penetrate it.

If we are correct in believing that all nerve tracts and trunks are derived from moniliform adhesions it is not a matter of so vital importance what source the successive elements of a series may have had.

In this connection we call attention to the following points respecting the olfactory from another group.

The relations of the olfactory apparatus of mammals may be particularly well demonstrated in mouse embryos at the stage when the vibrissæ are in process of early development. The specific olfactory apparatus in the epithelium need not be described, but the fibres arising from the ganglion cells of the olfactory epithelium may be traced back as one continuuus cord with an occasional sheath corpuscle attached until it enters the inter cranial space, here the fibre loses its sheath in the glomerulary mass This mass seems to contain, ist, sheath-forming corpuscles; $2 \mathrm{~d}$, corpuscles of the same sort as those which occupy the vicinity of the ventricles. The fibre, after passing into the glomerulary zone, subdivides dichotomonsly and is lost among the "protoplasmic processes" of the specific olfactory cells. It is as yet uncertain whether the latter are developed from the tuber (pes) or are an integral part of the pero brought thither by the proliferating olfactory epithelium.

There is a cell-less interval separating the specific olfactory cells from the glomerulary zone in which the fine branches of the former can be readily seen. The axis.cylinder process passes into a stratum just peripherad of the dense layer of (nu- 
tritive ?) corpuscles near the epithelium and enters the radix lateralis, which, at this stage, is well developed. There are still mitosis figures adjacent to the ventricle in the tuber as well as in certain parts of the olfactory epithelium.

The radix lateralis may be traced back to the ventro-lateral depression at the cephalic end of the pyriform lobe where a part of the fibres seem to dip directly into the substance and another part remains superficial and follows the depression named until the point of union with the lateral aspect of the thalamus is reached. A part of the fibres pass into the latter body to lose them selves among its cells.

\section{PIATE XV.}

Fig. 1. [206-3]. Section through the head of the youngest Eut $x$ nia embryos passing through the lense capsule and primary optic vesicle. The figure shows the connection of the lense capsule with the rest of the cephalic sensory plate (ceph.s. p.)

Fig. 2. [211-5]. Similar section of the second stage of Eutrenia (Plate XVI, Fig. 3.) The lense capsule has closed and the nasal sac is invaginating.

Fig. 3. A portion of the brain tube showing the relation of spongioblasts and neuroblasts. Dividing neuroblasts $(k)$ along the ventricular surface give rise to neuroblasts (n) which make their way among the spongioblasts ( $s p$.) to the surface, there to form the neurons.

Fig. 4. From $a$, Fig. 2. Numerous karyokinetic figures in the neublasts are visible and one or two instances of mitosis in the spongioblast nuclei (spl.) Well developed neurons are also scattered near the surface.

Fig. 5. From c, Fig. 2. The peripheral portion has already become reduced to a semi-gelatinous stroma in which the neurons in various stages are forming both axis cylinder and protoplasmic processes.

Fig. 6. A portion of the eyc and lense anlag in an embryo of the same age as Fig. 1 .

Fig. 7. A portion of the retina in Eutænia embryos of the same ages as Fig. 2, for comparison with the structure of the brain walls (Fig. 3.)

Fig. 8. Epithelium from the sensory plate near the nasal sac. (Fï. 2.) 
Fig. . E. Eithelium over the area from which the olfactory pit is to form, in youngest embryos of Futionia. [206-4].

The space between the epithelium and the cerebrum is occupied by the undifferentiated embryonic material.

Figs. 10-1\%. Portions of the olfactory epithelium in the middle stage of Eutania showing the origin and migration of the ganglion cells whence the olfactory nerve arises and passes to the tuber. [210 12].

PI.ATE XVI.

This plate illustrates the external appearance of the four broods of snake embryos described,

Fig. I. Entire germinal disc and embryo of the youngest Futænia (E. I) moderately enlarged.

Fig. 2. Head of the same, enlarged.

Fig. 3. Embryo of the same species, two days later.

Figrs 4-5. Fimbryo of the same species four days later than Fig. 3 .

figrs. 6-7. Black snake embryo taken July tgth.

\section{PI.ATE XVII.}

A series of perpendicular longitudinal sections through a Eutænia embryo of the agre figured in Plate XVI, Fig. 3. The sections are taken in such a way that, on account of the lateral curvature of the specimens, (compare Fig. 5, Plate XVI) the medulla is obliquely cut. The position of the median line is indicated by a star (s) in the several sections. $[209-7,6,5]$.

In Fig. I, the eye and ear vesicles are cut. Especial attention is called to the connection of the pituitary and nasal sac via a continuous columnar epithelium.

Fty 3 , especially illustrates the development of the trigeminal system.

Figs. 4 and 5 show the neuromeres of the medulla distinctly, - while Fig: 6, which is nearly mesal in front, has the theoretical axis of the

WIt should be sdded that the young are not burn until the latter part of July. .July 22, 1892, the young were fairly well developed and had two rows of dark spots on the dormon and splotehes ou the sides insteal of the stripes. The suakes were rнpable of motion though about one-uuarter of the yolk remained. The shell is transparent, not white like that of tho black suake. It secms legitimate to infer that the progeuitors of Futania were spotted like the Troppidonotus group. 
brain indicated by a dotted line as well as the boundaries of the several compartments.

\section{PIATE XVIII.}

Figs, 1-4. Four sections from a nearly horizontal series of the oldest embryo of Eutænia (Plate XVI, Figs. 4, 5.) The mesencephalon is obliquely cut and in Fig. 4 the roots of the oculo-motor (III) are in section. The medulla neuromeres are numbered beyond the isthmus as follows: V, VI. VII, IX, X, in accordance with the chief nerve. The isthmus has no nerve, its roof being formed by the cerebellum. Max + Mand. The maxillary and mandiblar parts of the trunk of the trigeminus, the opthalmic being obviously distinct from the first. [208.]

Figs.5-9. Five sections of the youngest Eutænia embroys [206]. Parts numbered as before. The neuromerism is quile as prominent as above.

Fig. 12. [207.] A section along the mid-dorsal region, showing that al though mesomerism is complete there is no neuromerism, $i$.e., although the muscular segments are well-formed, the neural tube is not segmented.

Figs. 10, Ir. Two scctions from the black-snake embryo; chosen to illustrate the substantial identity of neuromeric differentiation the two groups. [263.]

\section{PI.ATE XIX.}

Fis. 1. [207-5.] A somewhat oblique frontal section through the head of embryo of Futænia figured, Plate XVI, Figs. I, 2. [E. I.] The section is so taken that the caudal part of the mesenceplialon is cut, and a portion of the primary optic vesicle $10 p t$. $\}$ The existence of a distinct sensory plate passing from the hypophysis about the protuberance of the fore brain and including the lense capsule anlag is illustrated; the latter point being shown in Fig. 1, Plate XV.

Fig. 2. [205-3.] Portion of the walls of the diencephalon of the black-snake embryo figured in Plate XVI, Figs. 6, 7. The point from which the drawing is taken is Fig. $8 a$, of the present plate. This figure illustrates the elongation of the spongioblast $(s p)$, the dividing neurnblasts with karyokinetic figures $(k)$, the granule cells $(g r$.$) which are re-$ garded as indifferent nervous cells out of which neurons may be subsequently formed, the neuroblasts transforming into neurons $(n b$.) and giving off axis cylinders (a. c.), in this case, caudad, 


\section{i76 Jotrnal of Comparative Neurology.}

Fig. 3. Drawing of a part of the cerebral wall from an embry dog. The portion selected is from the frontal region and illustrates a similar process in a later stage.

Figs. 1 and 5. [204-7, 8.] Nearly perpendicular longitudinal sections through the head of embryonic black-snake (Plate XVI, Figs. 6, 7.) Both sections are near the lateral surface, Fig. 5 being the deeper. The neuromerism of the medulla is well shown.

Figs. 6 and 7. [202-7.] These figures are from the $h$ ir or five day chick embryo for comparison with those of Plate XVII. Tne chick is obviously in a somewhat later stage. The flexures are apparently less, but this is due to a backward revolution of the cerebral end.

Figs. 8. [205-3.] Horizontal section of the fore-head of a blacksnake embryo (Figs, 6, 7, Plaie XVI.) The formation of the lateral vesicles and the distinctly double character of the diencephalon are noteworthy.

Fig. 9. [208-9.] Section similar to Fig. 1, from oldest Eutania embryo. The section is immediately in front of the hypophysis and shows the upper jaw rudiments.

Fig. 10. Section through the auditory capsules of the Eutænia embryo figured Plate $X V I$, Fig. 3. The hyoid centrum is forming at $H$. $A u$, auditory vesicle. 